\title{
REDACTIONEEL
}

\section{Twintig jaar reflectie op herstelrecht}

\author{
Bas van Stokkom, Jacques Claessen \& Ivo Aertsen
}

In het vorige jubileumnummer schreven we dat de bekendheid van herstelrecht als theoretisch en sociaal-ethisch kompas nog altijd te wensen overlaat. Tegelijkertijd constateerden we dat er onder nieuwe lichtingen academici en professionals behoefte blijft bestaan om nader kennis te maken met herstelrecht, zijn methoden en de effectiviteit ervan en om kritische vragen te stellen bij het strafrechtelijke systeem (Blad \& Van Stokkom, 2015). Het herstelrecht blijft dus aantrekkingskracht uitoefenen, vooral de kerngedachte dat recht kan worden gedaan aan de direct betrokkenen, en wel op een voor hen herkenbare en door hen gedragen manier. Het gaat om de leefwereld van het slachtoffer en de dader, hun belangen en behoeften, hun verlangen betekenis en zin te geven aan wat er is gebeurd, samen met naasten en andere belanghebbenden en om de effecten ervan in termen van onder meer genoegdoening en zelfherstel (Blad, 2010).

\section{Pragmatisme}

Anno 2020 valt op dat de beleids- en politieke context rondom herstelrechtelijke voorzieningen in Nederland is veranderd. Mediation in strafzaken heeft sinds 2017 structureel een plek gekregen in de strafrechtspleging. In het Beleidskader herstelrechtvoorzieningen gedurende het strafproces van 8 januari 2020 geeft de minister voor Rechtsbescherming aan dat herstelrecht verder bevorderd dient te worden. Terwijl redactielid Renée Kool acht jaar geleden nog somberde dat er niet veel schot zat in mediation in strafzaken (Kool, 2012), zegt ze in dit nummer dat we tevreden mogen zijn: de receptie van het herstelrecht is sneller gegaan dan ze had verwacht. Maar die ontwikkeling roept naar haar mening ook vragen op. Want er is volgens haar nog altijd een reëel risico op een instrumenteel gebruik van herstelrechtelijke praktijken en een dergelijke toepassing draagt niet bij aan 'fatsoenlijke vergelding'. Zo heeft - om de achterstand in de afhandeling van strafzaken die is ontstaan door de coronacrisis, weg te werken - de Tweede Kamer op 21 september 2020 de motie van Van den Berge et al. aangenomen die ertoe strekt om meer gebruik te maken van mediation (Kamerstukken II, 2020/21 29279, nr. 612). Op zich goed nieuws, maar ook hier dient te worden gewaakt voor 'oneigenlijk gebruik'.

Mediation in strafzaken is op weg een 'mainstream' interventie te worden en een vast onderdeel van het justitiële beleid. Onze collega's in België zijn daar al langer vertrouwd mee en zijn er niet altijd even gelukkig mee. Zo zien veel strafrechtelijke professionals over het hoofd dat goed bemiddelen een bewerkelijke 
onderneming is waarvoor juist de tijd moet worden genomen (voor een overzicht van twintig jaar herstelrechtelijk beleid in België, zie Aertsen, 2021).

Gaandeweg worden de aspiraties van het herstelrecht meer en meer pragmatisch verwoord. De tijd van het abolitionisme en de Coornhert-Liga ligt inmiddels alweer ver achter ons. Het gaat thans niet om het omverwerpen van het strafrechtsysteem, maar om probleem- en conflictoplossing in de concrete leefwereld van betrokkenen. Die pragmatische benadering - primair gericht op verandering van de praktijk - houdt rekening met de belangen en behoeften van stakeholders en beoogt (verdere) schade te voorkomen en verminderen (Van Stokkom, 2016). Uiteraard komt het pragmatisme meer op de voorgrond te staan wanneer processen van institutionalisering zich hebben voorgedaan, waaronder een wettelijke basis voor herstelrechtelijke praktijken, structurele financiering, een vast organisatorisch kader, en opleiding en accreditering van bemiddelaars (Aertsen et al., 2006). Bovendien, de pragmatische inslag van de herstelrechtelijke beweging in Nederland is ongetwijfeld bevorderd door de komst van Restorative Justice Nederland, de overkoepelende organisatie die dit jaar haar tienjarige jubileum viert. De nadruk in die organisatie - met trekkers van het eerste uur Gert Jan Slump en Anneke van Hoek - ligt op het realiseren van projecten die bijdragen aan conflictoplossing, of het nu bemiddeling door de politie is, jongerenrechtbanken of herstelgerichte detentie.

Ook theoretische reflectie lijkt meer in het teken te staan van hervorming en aanpassing van het strafrechtelijke systeem dan gegrond op dogmatische beginselen. Illustratief in dat verband is het Voorstel van wet strekkende tot invoering van herstelrechtvoorzieningen in het Wetboek van Strafvordering (Claessen et al., 2018), dat veel aandacht voor herstelrecht heeft weten te genereren, vooral ook onder parlementariërs. Dit 'wetsvoorstel' geeft op heldere wijze aan hoe herstelrechtelijke uitgangspunten in het wetboek kunnen worden ingepast. De ontvangst van het 'wetsvoorstel' stemt tot tevredenheid.

Bij justitie blijkt de koudwatervrees voor herstelrecht inmiddels weggetrokken. Het 'Hulsman-syndroom' (Van Stokkom, 2012), de afkeer van alles wat riekt naar abolitionisme, lijkt minder impact te hebben, niet alleen op parlementariërs, maar ook op professionals als rechters en officieren van justitie. Zeker sinds de Raad voor de rechtspraak (2016) een effectievere rechtspleging op de agenda heeft gezet en meer aandacht wenst voor de achterliggende maatschappelijke problematiek en onderliggende conflicten, lijken justitiële professionals meer open te staan voor herstelrechtelijke initiatieven.

\section{Afscheid van 'purisme': van minimalisme naar maximalisme}

Het voorgaande neemt niet weg dat de herstelrechtelijke beweging nog altijd kritisch kijkt naar het automatisme waarmee in 'het strafrechtelijke bedrijf' (punitieve) sancties worden opgelegd. Ook in dat verband is de hiervoor genoemde 'proeve van wetgeving' illustratief te noemen. Bovendien is de weerstand tegen het dogma van intentionele leedtoevoeging nog altijd groot. Zelfs een eminente rechtsfilosoof als Antony Duff, die voorstander is van herstelgericht straffen, 
krijgt in dit verband veel kritiek te verduren. Het toebedelen van hard treatment aan de dader en de aanmoediging dat hij verantwoordelijkheid neemt voor zijn gedrag, gaan nu eenmaal moeilijk samen (Claessen, 2010).

De beweging heeft van begin af aan veel idealistische vertolkers in haar midden gehad. Er klonken veel waarschuwingen om niet al te snel met justitie in zee te gaan. De beweging mocht niet in het vaarwater komen van 'coöptatie'. Pleidooien voor 'purisme' - het idee dat de beste bemiddelingsresultaten buiten het strafrechtelijke systeem kunnen worden bewerkstelligd (McCold, 2000) - konden rond de eeuwwisseling op veel instemming rekenen. Deze 'minimalistische' visie stelt vooral vrijwillige deelname en het communicatieproces tussen de betrokkenen in het conflict voorop.

Daartegenover heeft Lode Walgrave (2009) met zijn 'maximalistische' visie ervoor gepleit dat herstelgerichte sancties die binnen het bestaande systeem worden opgelegd, zinvol kunnen zijn. Indien vrijwillige overeenkomsten niet mogelijk zijn, kunnen die sancties - bijvoorbeeld de verplichting om onbetaalde (herstel)werkzaamheden op zich te nemen of om schade te vergoeden - een betere oplossing brengen voor zowel daders als slachtoffers (zie ook Restorative Justice Nederland, 2011; Claessen, 2010).

Mediation en herstelbemiddeling hoeven dus niet op afstand te blijven van het strafrecht. Als een opgelegde herstelsanctie gedragsverandering met zich brengt, is dat winst. En als een slachtoffer voorafgaand aan vervolging van de verdachte een gesprek in het kader van mediation in strafzaken wenst, is het fijn dat hem die gelegenheid geboden kan worden. De behoeften van de partijen staan voorop.

\section{Toenemend inzicht in een weerbarstige mediationpraktijk}

Een andere verschuiving in denken en doen heeft betrekking op de rol van de mediator. In de begintijd klonk de standaardvisie van een terughoudende en onpartijdige mediator nog sterk door. Veel mediators gingen blindelings af op de beginselen van neutraliteit, vrijwilligheid en vertrouwelijkheid die gangbaar waren (en zijn) in het civiele recht. Dat is inmiddels bijgesteld. Want in een strafrechtelijke context kan niet aan het beginsel van 'neutraliteit' worden beantwoord. Intussen spreken mediators liever over 'meerzijdige partijdigheid', een term die uit de psychotherapie stamt en erop wijst dat de mediator afhankelijk van wat nodig is, wisselend betrokken is op de deelnemende partijen (Bijlsma \& Dierx, 2017). Vooral Janny Dierx heeft in dit tijdschrift herhaaldelijk gewezen op politieke kenmerken van mediation, waarvan leidinggeven en confronteren belangrijke ingrediënten zijn (Bijlsma \& Dierx, 2015; Dierx \& Van Stokkom, 2018; zie ook Mual, 2020). In de context van diep geëscaleerde en complexe conflicten spreekt dat vanzelf. Tegelijkertijd blijven Dierx en veel collega-mediators kritisch kijken naar het strafrechtelijke bedrijf en waarschuwen voor een 'McDonaldisering' van mediation, inclusief copy-paste-gedrag en 'mooi-weer-tegoedbonnen' (Dierx \& Panis, 2018).

Inmiddels is ook het beeld van vrijwilligheid bijgesteld. Erkend wordt dat in de praktijk regelmatig 'druk' wordt uitgeoefend op partijen om mee te doen en op 
daders om oprecht sorry te zeggen. Soms ook om strategische redenen, want op de achtergrond dreigen strafrechtelijke gevolgen. Dat heeft kritiek opgeroepen, op klassieke wijze vertolkt door Annelise Acorn (2004) en in Nederland door Vincent Geeraets (2014), die in dat verband spreekt over de 'herstelrechtelijke fictie' van vrijwilligheid. Anderen nuanceren deze kritiek door erop te wijzen dat geen enkele beslissing of keuze zich afspeelt in een vacuüm en dat informeren, stimuleren en overtuigen nog niet betekenen dat daarmee iedere keuzevrijheid verdwijnt (Claessen, in dit nummer). Niettemin zien we ook hier dat de oorspronkelijke term vrijwilligheid steeds vaker plaatsmaakt voor de term die de lading waarschijnlijk beter dekt: informed consent (zie ook Claessen et al., 2018).

Het voorgaande is geen pleidooi om het beginsel van vrijwilligheid maar los te laten, integendeel. Hoewel vrijwilligheid van deelname doorgaans goed geborgd is, worden (jonge) verdachten in het voortraject soms onder druk gezet om deel te nemen (Wolthuis, 2012; Cleven et al., 2015). Het uitoefenen van sociale druk is sociologisch bezien een vanzelfsprekend verschijnsel: bekenden, vrienden en verwanten 'duwen' een dader of slachtoffer vaak naar de mediationkamer of houden hem daarvan juist af. Ook tijdens de bijeenkomsten wordt morele druk uitgeoefend. De deelnemers zijn onderworpen aan een 'emotioneel regime' dat impliciet druk zet op de deelnemers, de mediators incluis, om zich te houden aan de rollen van oprecht spreken en coöperatief meedenken (Van Stokkom, 2019). Jonge daders slagen er lang niet altijd in daaraan te voldoen. Niet omdat sorry zeggen een strategisch doel dient, maar omdat de sociaal-emotionele lat van het gesprek (te) hoog ligt (zie ook Johnstone, 2020; Wood, 2020).

Het voorgaande kan worden opgevat als 'volwassenwording' van herstelrechtelijke praktijken. Onderkend wordt dat mediation plaatsvindt in een weerbarstige realiteit. Met betrekking tot de vraag hoe meer grip te krijgen op die realiteit - bespreekbaar maken van schaamtegevoelens; nut en zin van het excuus - is inmiddels behoorlijk wat onderzoek beschikbaar. Ook het gegeven dat daarover aanhoudend debatten plaatsvinden, kan als een teken van volwassenheid worden gezien. In dit tijdschrift is sowieso veel discussie gevoerd en in die debatten werden soms harde noten gekraakt. Zo is de visie van Lode Walgrave en zijn pleidooi voor reparatieve sancties (Walgrave, 2009) door sommigen van (fel) commentaar voorzien. Zo meende rechtsfilosoof Paul de Hert dat het civiele recht het geëigende domein is voor schadevergoeding (De Hert, 2009; voor een repliek zie Walgrave, 2010). Daarnaast is debat gevoerd rondom de rechten en behoeften van slachtoffers: de trend van therapeutisering (Daems, 2007 en 2008; Pemberton, 2008), de emancipatie van het slachtoffer (Van Dijk, 2009) en de victimalisering van het strafproces en het (onbeperkt) spreekrecht (Blad, 2013; Dierx, 2013). Zolang dergelijke discussies in dit tijdschrift gevoerd worden, wordt de geest aangescherpt en kunnen doeleinden en ambities indien nodig worden bijgesteld. 


\section{De artikelen}

In dit nummer zijn columns opgenomen van de twee herstelrechtelijke founding fathers in het Nederlandstalige gebied, tenminste als we het klassieke strafrechtskritische werk van Herman Bianchi en Louk Hulsman terzijde laten. John Blad vestigt nogmaals de aandacht op strafrechtelijke stereotyperingen en mythes over goed en kwaad. Lode Walgrave pleit ervoor dat de herstelrechtelijke beweging op termijn het strafrecht zou kunnen ombuigen tot een delictenrecht.

In dit nummer bieden acht redacteuren van dit tijdschrift vanuit hun eigen intellectuele affiniteiten en interessevelden inzicht en uitzicht. Jacques Claessen lijkt aan de ambitie die Walgrave in zijn column schetst, te willen voldoen: hij schetst de contouren van een maximalistisch herstelrecht dat in veel opzichten uitmondt in een delictenrecht - dat hijzelf in navolging van Bianchi misdaadrecht noemt. Het artikel biedt veel stof tot nadenken. Vanuit een ander perspectief sluit Renée Kool daarop aan: zij geeft in haar artikel een constructieve betekenis aan vergelding. Dat geldt ook voor de bijdrage van Bas van Stokkom die focust op John Blads visie op het herstelrechtelijke sanctiebegrip. Ivo Aertsen en Anneke van Hoek schetsen ieder op hun eigen manier hoe de herstelrechtelijke beweging kan aansluiten op fundamentele maatschappijkritiek en haar vleugels verder zou kunnen uitslaan binnen de civil society. Ten slotte zijn drie artikelen opgenomen die inzoomen op aspecten van het herstelrecht waar de auteurs zelf veel onderzoek naar hebben verricht. Sven Zebel gaat in op de werkzame ingrediënten van herstelrechtelijke sancties, Alice Bosma geeft aan welke slachtofferbeelden in de loop der tijd in dit tijdschrift zijn ontvouwd en Annemieke Wolthuis brengt de ontwikkelingen naar een 'volwassen' herstelgericht jeugdrecht in kaart.

Ten slotte, vanaf volgend jaar (jaargang 21) gaat het tijdschrift van vier naar drie nummers per jaargang. Dat heeft niet te maken met kopijgebrek - de nummers zijn de laatste jaren eerder dikker geworden - maar is vooral een kwestie van anders organiseren: er ontstaat meer ruimte om in elk van de drie nummers het themagedeelte te combineren met varia-artikelen en rubrieken die niet aan het themagedeelte zijn gebonden, waaronder discussie, boekbesprekingen en signalementen.

\section{Literatuur}

Acorn, A. (2004) Compulsory compassion: a critique of restorative justice. Vancouver: University of British Columbia Press.

Aertsen, I. (2021, n.n.g.) Evoluties in het herstelrechtbeleid 2000-2020, Panopticon.

Aertsen, I., T. Daems \& L. Robert (eds.) (2006), Institutionalizing Restorative Justice. Cullompton: Willan Publishing.

Bijlsma, J. \& J. Dierx (2017) Mediation in Strafzaken, in: A. Brenninkmeijer (red.), Handboek Mediation (pp. 599-612). Den Haag: Sdu Uitgevers.

Bijlsma, J. \& J. Dierx (2015) Werelddialoog aan de mediationtafel. Tijdschrift voor Herstelrecht, 15(3), 77-86. 
Blad, J. (2010) Tien jaar Tijdschrift voor herstelrecht. Tijdschrift voor Herstelrecht, 10(4), 7-12.

Blad, J. (2013) Victimalisering van het strafproces. Tijdschrift voor Herstelrecht, 13(1), 38-49.

Blad, J. \& B. van Stokkom (2015) Vijftien jaar Tijdschrift voor Herstelrecht: een plaatsbepaling. Tijdschrift voor Herstelrecht, 15(3), 3-8.

Claessen, J. (2010) Misdaad en straf. Een herbezinning op het strafrecht vanuit mystiek perspectief. Nijmegen: Wolf Legal Publishers.

Claessen, J. et al. (2018) Voorstel van wet strekkende tot invoering van herstelrechtvoorzieningen in het Wetboek van strafvordering, inclusief Memorie van Toelichting. Oisterwijk: Wolf Legal Publishers.

Cleven, I. et al. (2015) De rol van herstelbemiddeling in het strafrecht. Tilburg: Intervict.

Daems, T. (2007) De slachtofferdimensie van herstelrechtelijke interventies: Een sluimerende therapeutisering? Tijdschrift voor Herstelrecht, 7(1), 7-21.

Daems, T. (2008) Victimologen met stekelvacht. Een reactie op Pemberton en Wemmers. Tijdschrift voor Herstelrecht, 8(4), 45-52.

Dierx, J. (2013) Spreken is zilver, praten is goud. Tijdschrift voor Herstelrecht, 13(1), 23-33.

Dierx, J. \& M. Panis (2018) Risico's rondom de eindovereenkomst bij mediation in strafzaken. Over (de)juridisering, strijdige belangen en management van verwachtingen. Tijdschrift voor Herstelrecht 18(2), 25-42.

Dierx, J. \& B. van Stokkom (2016) Herstelbemiddelaars: hun kwaliteiten en hun politieke rol. Tijdschrift voor Herstelrecht, 16(3), 28-31.

Dijk, J. van (2009) De komende emancipatie van het slachtoffer. Tijdschrift voor Herstelrecht, 9(1), 20-39.

Geeraets, V. (2014) Herstelrechtelijke ficties. Rechtsgeleerd Magazijn Themis, 175(2), 72-79.

Hert, P. de (2009) Waarom herstel niet tot de kerntaken behoort. Bedenkingen bij Walgraves rechtsonbehagen. Tijdschrift voor Herstelrecht, 9(3), 39-46.

Johnstone, G. (2020) Voluntariness, coercion and restorative justice: questioning the orthodoxy. The International Journal of Restorative Justice, 3(2), 157-167.

Kool, R. (2012) Tussen hoop en vrees. Toepassing van herstelrecht in het buitengerechtelijk spoor, Tijdschrift voor Herstelrecht, 12(1), 11-26.

Mual, M. (2020) Mediation in strafzaken: de werkstijl is de methode. Reflecties op de praktijk. Tijdschrift voor Herstelrecht, 20(3), 49-64.

Pemberton, A. (2008), Over egels, vliegen vangen en herstelrecht. Een reactie op Daems, Kaptein en Walgrave. Tijdschrift voor Herstelrecht, 8(4), 53-65.

Restorative Justice Nederland (2011) De toepassing van herstelrecht in Nederland: bouwstenen voor een toekomstvisie. Amsterdam (www.restorativejustice.nl/user/file/ visierjn7oktoberextern2012.pdf).

Stokkom, B. van (2019) Complying with display rules: the managed heart in restorative justice. Complementing ritual theories of emotional bonding. The International Journal of Restorative Justice, 2(3), 429-450.

Stokkom, B. van (2012) Avances naar herstelrecht. Het 'Hulsman-syndroom' voorbij? Tijdschrift voor herstelrecht, 12(1), 57-63.

Stokkom, B. van (2016) The 'miraculous' emergence of penal mediation in the Netherlands. Restorative justice in the context of Dutch pragmatism and populism. Plenary Presentation, Conference EFRJ, Leiden, June 22-25 https://basvanstokkom.eu/wp-content/ uploads/publications/2016_05_AE_MiraculousEmergenceMediation.pdf.

Walgrave, L. (2009) Een maximalistische visie op herstelrecht. Tijdschrift voor Herstelrecht, 9(3), 19-38. 
Walgrave, L. (2010) De maximalistische visie op herstelrecht onder vuur. Tijdschrift voor Herstelrecht, 10(1), 21-35.

Wood, W. (2020) The indecent demands of accountability: trauma, marginalisation, and moral agency in youth restorative conferencing. The International Journal of Restorative Justice, 3(2), 168-193.

Wolthuis, A. (2012) Herstelrecht, een kinderrecht. Voorstellen voor integratie van herstel in het hart van het jeugdstrafrecht. Den Haag: Boom Lemma Uitgevers. 